\title{
periferio
}

\section{COMPARTILHANDO O ESPÍRITO E MANTENDO A CHAMA DA JUSTIÇA SOCIAL}

\author{
Rosangela Malachias ${ }^{1}$ \\ Universidade do Estado do Rio de Janeiro - UERJ \\ Elizabeth C. Reilly ${ }^{2}$ \\ Loyola Marymount University \\ Kay Fuller ${ }^{3}$ \\ University of Nottingham
}

Desde a sua primeira conferência realizada em Roma, em 2007, as integrantes do grupo Women Leading Education (WLE) começaram a expandir a sua compreensão teórica sobre mulheres na liderança educional apresentando teorias e traçando internacionalmente o perfil dos avanços, sucessos e desafios dessas mulheres líderes. Criamos oportunidades organizativas para nos reunir em conferências bianuais, como participantes acadêmicas e ativistas, mas também para estender e somar o nosso trabalho intercontinental a inúmeras iniciativas de pesquisa.

Em todo esse trabalho já realizado - apresentações em conferências e publicações colaborativas - as colegas do grupo WLE intercambiam mensagens, ações, sonhos, sofrimento e triunfo. Nossas pesquisas e apelos à necessária (re)ação internacional refletem dois temas principais. Primeiro, eles nos pedem para estarmos conscientes do imperativo moral da liderança das mulheres em

\footnotetext{
1 Doutora em Ciências da Comunicação pela ECA-USP Escola de Comunicações Artes da Universidade de São Paulo, com bolsa do Fundo Rioychi Sasakawa (Japão).É Professora Adjunta da UERJ-FEBF - Universidade do Estado do Rio de Janeiro - Faculdade de Educação da Baixada Fluminense no Departamento de Ciências e Fundamentos da Educação. É membro do grupo WLE desde 2007, na $1^{\text {a }}$ conferência em Roma. rosmalach@gmail.com

$2 \mathrm{PhD}$ in Education - Ed.D -Organization and Leadership at University of San Francisco. MA Teaching and Curriculum and Urban Leaders Instructions; BA English and Communication Arts both at University of the Pacific. Professor \& Department Chair of Educational Leadership at School of Education - Loyola Marymount University. Los Angeles, California. Member of WLE Group since the First Conference in Rome, 2007. elizabeth.reilly@lmu.edu

$3 \mathrm{PhD}$ focused on Gender and Secondary School Leadership. She is Associate Professor of Educational Leadership at University of Nottingham. Prior to that she was Lecturer in Education, and course leader of the secondary English PGDipEd at the University of Birmingham (2007-2014). Kay is Member of WLE Group since the First Conference in Rome, 2007. kay.fuller@nottingham.ac.uk
}

Periferia, v. 10, n. 2, p. 05-12, jul./dez. 2018

DOI: 10.12957/periferia.2018.35860 


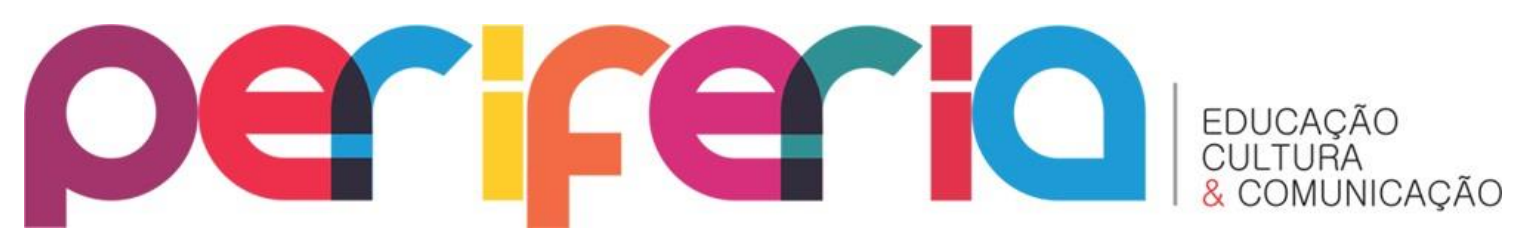

abordar as questões mais críticas, que nossa sociedade global enfrenta. Questões de acesso aos direitos básicos de todos os seres humanos: à liberdade, à justiça e à equidade. Em segundo lugar, os temas nos pedem para reconhecer que, ao agirmos juntas, cumprimos as responsabilidades que nos são confiadas.

Sistematicamente, cada vez que nos reunimos, nos comprometemos com a organização de uma publicação baseada no trabalho de pesquisa ou intervenção apresentado. Cada conferência atrai estudiosas(os) e profissionais reconhecidas(os) internacionalmente propiciando pesquisas colaborativas, que exploram o status das mulheres na liderança educacional. Nosso trabalho é um convite ao desenvolvimento de políticas globais, destacando a liderança educacional das mulheres como uma questão crítica de justiça social. Assim, as publicações WLE - livros e revistas - são produto acadêmico de todas as conferências.

LYMAN, L. \& Strachan, J.. Shaping social justice leadership: Insights of women educators worldwide. Lanham, MD: Rowman \& Littlefield Education, 2012.

MCNAE, R. \& Reilly, E. C. (Eds.) Women leading education across the continents: Finding and harnessing the joy in leadership. Lanham, MD: Rowman \& Littlefield Education, 2018.

REILLY, E. C. \& BAUER, Q. (Eds.) Women leading education across the continents: Overcoming the barriers. Lanham, MD: Rowman \& Littlefield Education, 2015.

SOBEHART, H. C. (Ed.). Women leading education across the continents: Sharing the spirit, fanning the flame. Lanham, MD: Rowman \& Littlefield Education, 2009.

Em suma, foi nesse espírito que este Dossiê da Revista Periferia da Universidade do Estado do Rio de Janeiro - Faculdade de Educação da Baixada Fluminense (UERJ-FEBF) tornou-se a primeira publicação bilingue da coleção WLE.

A Revista Periferia (UERJ-FEBF) define o conceito de Periferia "não apenas como localização geográfica de certas regiões” e seus aspectos sociais e econômicos, mas também como local onde "os fenômenos sociais e as manifestações culturais de caráter experimental, inovador ou alternativo" se 


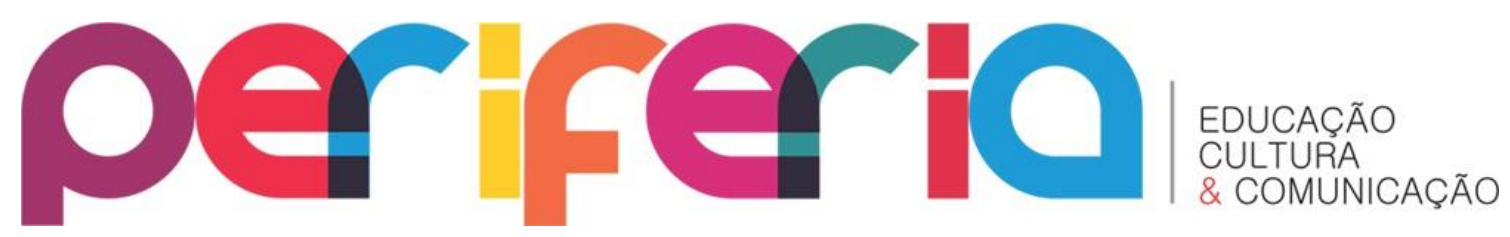

manifestam. O conceito designa novos cenários, novos modos de apropriação e produção cultural” (REVISTA PERIFERIA).

Segundo o Instituto de Pesquisas e Análises Históricas da Baixada Fluminense (IPAHB), a região - Baixada Fluminense, BF - está localizada entre o litoral do Estado do Rio de Janeiro e a Serra do Mar. É formada por um relevo de baixas planícies cobrindo apenas os municípios localizados ao norte da cidade do Rio de Janeiro. Os municípios da BF são: Belford Roxo, Duque de Caxias (onde fica a FEBF, um dos sete campi da UERJ), Guapimirim, Itaguaí, Japeri, Magé, Mesquita, Nilópolis, Nova Iguaçu, Paracambi, Queimados, São João de Meriti. Seropédica.

Há algumas décadas, essa região era conhecida como a Baía de Guanabara, sudeste do Brasil. Desde os anos setenta, durante o período da ditadura militar (1964-1985), a BF passou a significar a fusão entre os contextos geográfico, social e cultural. Suas cidades dormitórios passaram a registrar altos níveis de violência, mais precisamente assassinatos, explicados pela ausência de políticas públicas (IPAHB, 2007) e vontade política dos diferentes órgãos governamentais.

Simultânea e paradoxalmente, os movimentos locais e sociais têm trabalhado para desenvolver práticas e discursos contra a violência e os estereótipos persistentemente direcionados a esta região. Tais ações ocorrem principalmente nas esferas da cultura, como música e cinema; educação e organização de coletivos para a defesa dos direitos. A BF tornou-se também uma região em que a participação coletiva surge como resistência periférica em cultura. É a Periferia mostrando suas subjetividades e interseções das margens para os centros.

Nesta edição especial, a Revista Periferia - Online - reúne autoras e autores que apresentaram seus estudos e pesquisas na 6th Women Leadind Education Conference-From Margins to Centers [Conferência Mulheres Líderes em Educação - Das Periferias aos Centros], em Duque de Caxias, RJ - de 23 a 29 de julho de $2017^{4}$. 0 evento comemorou 10 anos do grupo internacional WLE

\footnotetext{
${ }^{4}$ Evento científico apoiado pela CAPES/PAEP.

Periferia, v. 10, n. 2, p. 05-12, jul./dez. 2018

DOI: $10.12957 /$ periferia.2018.35860
} 


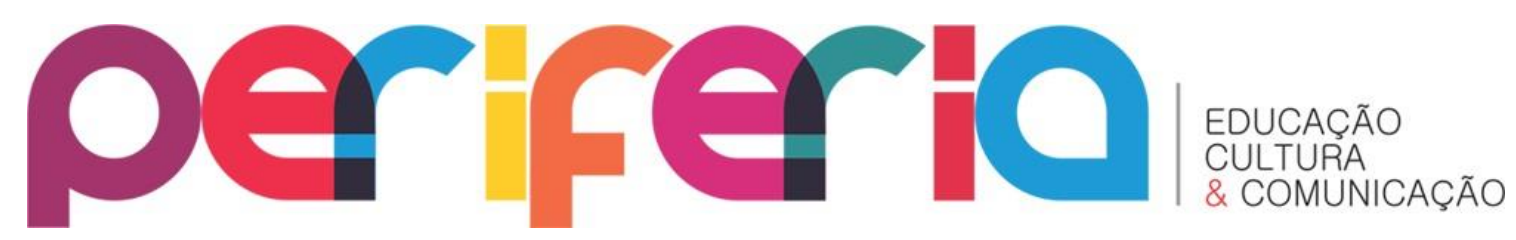

formado por Mulheres scholars de diferentes países e continentes que, desde 2007, estudam e trabalham para a implementação da justiça social nas instituições educacionais, organizações não governamentais e sociedade.

A rede WLE está crescendo apesar da perda de direitos em curso no mundo. Segundo o Relatório das Nações Unidas (2016), as disparidades de gênero são mantidas e perpetuadas, inclusive nas carreiras acadêmicas. As universidades precisam promover a igualdade entre homens e mulheres, no entanto, a adoção da justiça social não é tarefa fácil em um contexto histórico e cultural, no qual os estereótipos de gênero atuam como crenças para manter a subalternização feminina.

O ensino básico e superior deve contribuir para a compreensão dos direitos humanos e para a erradicação da violência. O Brasil registra alto índice do crime feminicídio (assassinato de mulher por causa de sua condição de gênero). De acordo com dados divulgados pelos Procuradores dos Estados, pelo menos oito casos de feminicídio ocorreram no país por dia, entre março de 2016 e março de 2017. No total, houve 2925 casos do crime feminicídio; $8,8 \%$ a mais do que o índice apurado no ano anterior (Ministério Público, Março/2017).

O Brasil também vive um período excepcional desde 2016, quando Dilma Roussef, a primeira mulher eleita como Presidenta foi submetida a um processo de impeachment. A política econômica nacional responde a uma demanda neoliberal de privatização e redução de políticas sociais. Além disso, escândalos de corrupção aprofundam a crise, além da ampliação do número de desempregados em todo o pais.

A UERJ - Universidade do Estado do Rio de Janeiro - uma das melhores instituições de ensino superior do Brasil - não está fora deste cenário. Ela vem sendo submetida a cortes financeiros, que afetaram diretamente o pagamento de salários do corpo docente e dos funcionários; assim como o atraso das bolsas de estudo para estudantes. Essa política governamental prejudica diretamente o acesso e a permanência de estudantes das classes menos favorecidas; cotistas e ainda compromete a qualidade dos projetos de pesquisa e extensão da universidade, cuja tradição é de ser uma instituição pública socialmente referenciada. 


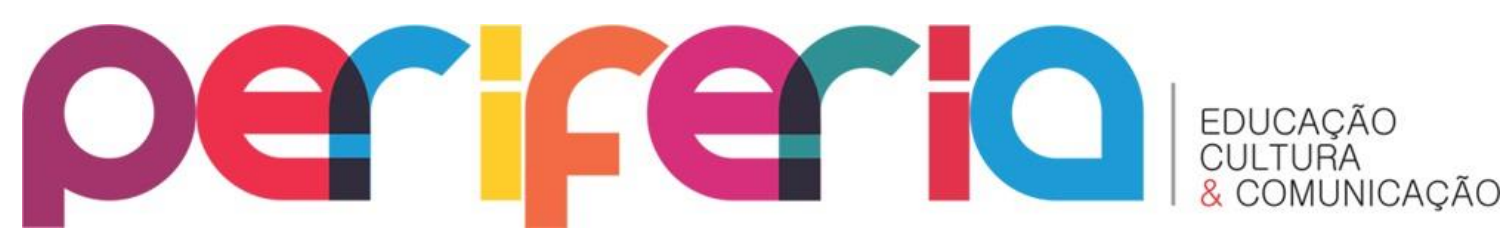

\#UERJResiste! tornou-se um slogan e símbolo da luta na defesa e resistência da educação pública. O primeiro semestre de 2017 foi provavelmente o período mais difícil para os estudantes, técnicos e professores que estudam, trabalham e ensinam na UERJ. No entanto, dois anos antes, em 2015, o Brasil havia sido escolhido para sediar a $6^{\text {a }}$ Conferência WLE durante a eleição feita na $5^{a}$ Conferência WLE realizada na Universidade de Waikato, Hamilton, Nova Zelândia.

Em maio de 2016, por meio de votação por e-mail, o tema "Das Periferias aos Centros" foi o vencedor do encontro programado para julho de 2017, no campus da FEBF, Duque de Caxias, BF. Porém, por falta de pagamento de salários e por respeito à paralisação dos trabalhadores do campus, a coordenadora ${ }^{5}$ local, docente da FEBF, firmou parceria com a Secretaria de Cultura de Duque de Caxias para ocupar a Biblioteca Municipal Leonel de Moura Brizola. A parceria extendeu-se ao uso das salas da Escola SESI, ambas no centro da cidade.

Construir e manter uma rede científica e social com o compromisso sério com a agenda de justiça social não é um trabalho fácil. No entanto, durante 10 anos, de julho de 2007 até hoje, o grupo de acadêmicas e ativitas WLE - Women Leading Education cresceu no mundo e esse crescimento não é quantitativo em número de membros, mas pode ser medido pelo aprimoramento de questões sobre justiça social direcionada às mulheres.

0 crescimento da rede inclui membros de todos os continentes e sua compreensão sobre a relevância do status das mulheres e meninas nos sistemas de educação e na sociedade. Reunir acadêmicas de diferentes continentes para a $6^{\text {a }}$ Conferência WLE no BF - Baixada Fluminense - foi também uma escolha para a perspectiva das Margens, ou seja, da Periferia, ao invés da opção pelo centro (realizar o evento na zona sul do RJ, por exemplo).

Essa escolha pela Periferia refletiu no Programa da Conferência e nos tópicos interseccionais. Liderança e Gênero; Liderança e Direitos Humanos; Etnia; População Tradicional; Educação Formal e Não Formal.

\footnotetext{
5 Profa. Dra. Rosangela Malachias.

Periferia, v. 10, n. 2, p. 05-12, jul./dez. 2018

DOI: $10.12957 /$ periferia.2018.35860
} 


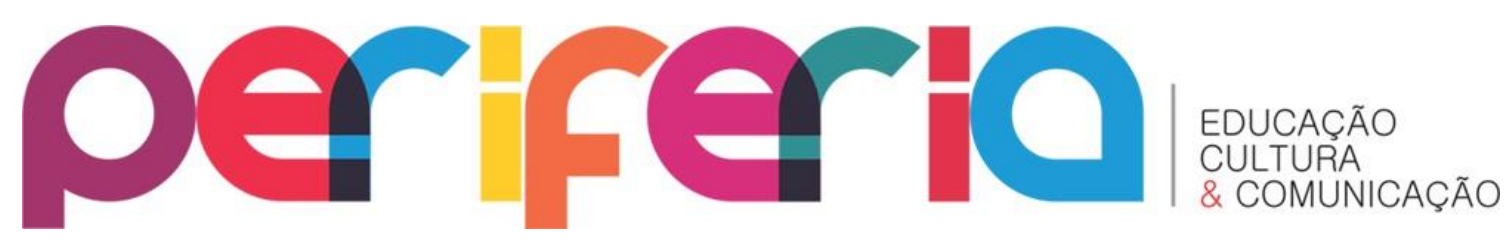

Entre 94 participantes, 55 artigos foram apresentados por pesquisadoras de 12 países $^{6}$. Esta edição da Revista Periferia é uma gota neste oceano de pessoas e de saberes. Nos artigos brasileiros, as/os leitoras/es podem aprender sobre a relação entre oralidade e escrita na escola indígena Guarani Mbya, no Rio de Janeiro. As autoras relatam a educação vista sob a perspectiva feminina de uma professora Guarani, que trabalha há mais de dez anos na escola dirigida ao seu povo.

Dois artigos enfocaram o estado de Mato Grosso. Uma professora negra que trabalha em uma escola primária na região do Vale do Arinos, MT, tornouse uma referência relevante para outras/os educadoras/es, pois as suas metodologias foram particularmente desenvolvidas com o objetivo da implementação da Lei Federal 10.639/2003 sobre o Ensino de Cultura e História Afro-Brasileira e Africana.

O papel do patriarcado na vida das mulheres que integram a população tradicional, que vive em áreas rurais do estado de Mato Grosso foi objeto de estudo e das práticas realizadas pelo Centro de Desenvolvimento Territorial da Baixada Cuiabana da Universidade do Estado do Mato Grosso. 0 artigo expõe como comitês de mulheres quilombolas ${ }^{7}$ e de jovens foram criados para enfrentar e alterar as disparidades de gênero.

Em 1882, seis anos antes da abolição da escravidão no Brasil (1888), um colégio católico para meninas chamado Educandário Nossa Senhora da Piedade começou a ser construído na cidade de Paraíba do Sul, Estado do Rio de Janeiro obedecendo ao testamento de Mariana Claudina Pereira de Carvalho. A Condessa de Rio Novo, como era conhecida e a história do Educandário são temas desse interessante período, no qual as mulheres não acessam a educação formal.

A representatividade do gênero feminino em materiais educacionais pode reproduzir e perpetuar estereótipos. Esta afirmação, dentre outras

\footnotetext{
${ }^{6}$ Australia, Brazil, Ghana, England, India, Kenya, New Zealand, Nigeria, Pakistan, Philippines, Uganda, United States.

7 No passado, os Quilombos foram criados por negros que escaparam da escravidão como povoados fortificados, dotados de divisões e organização interna. Após a abolição, os habitantes dessas terras passaram a ser identificados como Quilombolas.
} 


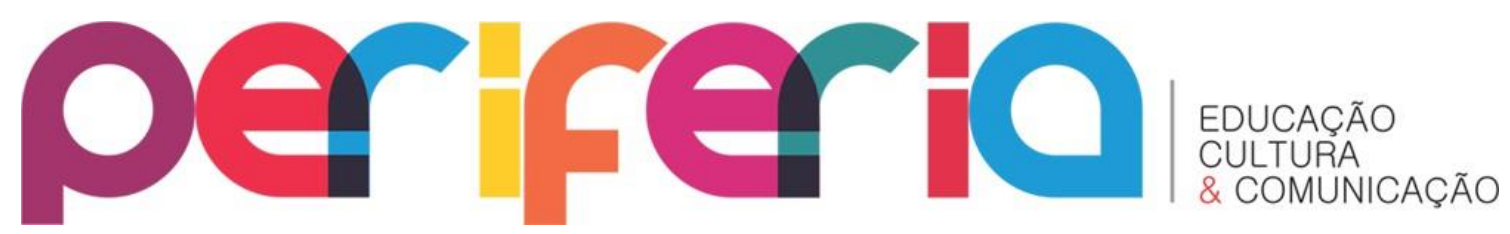

conclusões, está no artigo sobre um livro específico - Tosco... - que é amplamente utilizado nas escolas públicas brasileiras como apoio didático à prevenção de drogas. A narrativa descreve os personagens femininos sob uma visão estereotipada e, apesar da relevância que a prevenção às drogas tem, de outra forma, o livro reforça as desigualdades de gênero.

$E$ as desigualdades de gênero aparecem também na representatividade das mulheres na política. 0 artigo mostra uma linha histórica da presença feminina na política da cidade de Duque de Caxias, na Baixada Fluminense, RJ. As autoras afirmam, que o fato de uma mulher ser protagonista no ambiente político e ocupar cargos de responsabilidade e poder apresenta constrangimentos e incompatibilidades com as persistentes representações femininas na sociedade brasileira.

O último texto brasileiro é uma entrevista dupla, ou seja, com duas mulheres negras líderes em questões de cultura e educação em Ribeirão Preto, SP, cidade conhecida como "a Califórnia brasileira". 75 anos de idade e ativismo social no Movimento das Mulheres e no Movimento Negro unificam suas histórias. Ambas pertencem à Casa da Mulher / Casa da Mulher, uma organização não governamental que trabalha para o empoderamento de meninas, jovens e mulheres. A poesia é a "arma" contemporânea usada por ambas no evento local (e global) Sarau Preto.

As contribuições em inglês para este número especial incluem trabalhos que enfocam a experiência de mulheres negras na liderança educacional nos Estados Unidos, práticas de orientação de mulheres e um relato da experiência de crianças deficientes em educação na Índia. Esses artigos enfocam o trabalho da Women Leading Education de várias maneiras. Primeiro, o estudo autoetnográfico de quatro mulheres negras assegura que as suas vozes sejam ouvidas em alto e bom som, por contextualizar em um relato, o legado da escravidão nos Estados Unidos. O texto é um poderoso lembrete do impacto dos contextos históricos e sociais no trabalho das(os) educadoras(es). Este exemplo de pesquisadoras falando em suas próprias vozes ressoa com a publicação de Shaping Social Justice Leadership (LYMAN, STRACHAN e LAZARIDOU, 2012). Esse livro dá voz às mulheres que participaram do WLE em todos os continentes. 


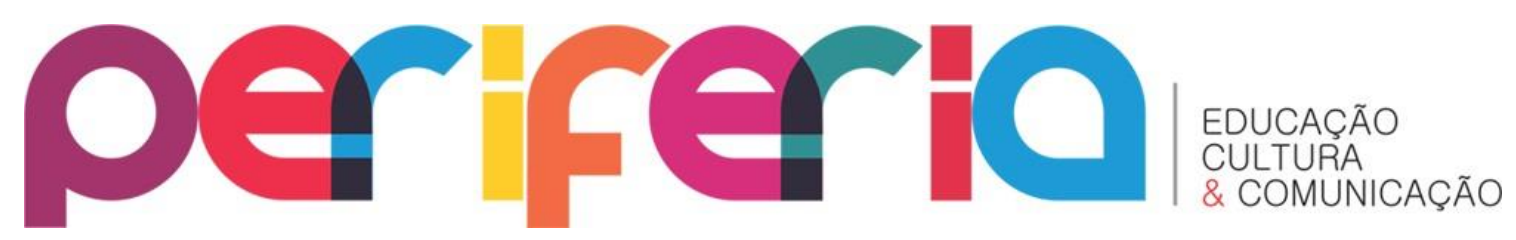

Assim também, a recomendação feita no final do artigo ressoa na rede WLE de acadêmicas e ativistas, que enfatizam a comunidade e a colaboração.

O segundo artigo centraliza as práticas de mentoria das mulheres, uma vez que relata a experiência de gestoras de escolas seguindo um guia de orientação às diretoras principiantes. Este artigo enfatiza a importância da liderança relacional (GROGAN e SHAKESHAFT, 2011); o sentido das relações horizontais, que permitem às mulheres usar o poder para capacitar, em vez de controlar. A autora recomenda que as/os estudiosas(os) procurem exemplos de orientação em equipe para desviar o foco de um modelo diádico.

No terceiro artigo em inglês, os autores focam na educação de crianças deficientes na Índia lembrando-nos o objetivo do grupo WLE na ênfase à liderança e justiça social. Este artigo é uma contribuição bem-vinda para uma literatura limitada sobre deficiência e educação na Índia.

O quarto artigo começa com uma breve visão geral do significado da resiliência e descreve o ciclo de resiliência que as mulheres líderes experimentam quando ocorrem as adversidades.

A última contribuição é uma entrevista com uma líder paquistanesa e os desafios sobre a lacuna nas abordagens de gênero na sociedade global.

Este dossiê congrega a nossa busca contínua, na medida em que construímos e expandimos a comunidade WLE e documentamos o status das mulheres líderes internacionalmente. É nossa esperança que nestas páginas você leitor(a) encontre inspiração para o seu intelecto enriquecendo a sua imaginação para continuar o trabalho iniciado, nos diferentes continentes, por mulheres na liderança educacional. 